\title{
Equilíbrio Orçamentárıo
}

\section{ASPECTOS SOCIAIS E ECONOOMICO-FINANCEIROS}

\author{
Rubem Barreto Ribeiro
}

$\mathrm{P}$

$$
\text { I - DEFINIÇÃO }
$$
Numa situação de equilibrio orçamentário os gastos governamentais, despendidos na satisfação das necessidades públicas, se igualam aos recursos obtidos através de sua atividade financeira para custeá-los.

\section{II - TIPOS BÁSICOS DE EQUILÍBRIO ORÇAMENTÁRIO}

Tendo em vista as diversas fases do processo orçamentário podem ser distinguidos, segundo o Prof. A. Barsante dos Santos, os seguintes tipos básicos de equilibrio:

1. Equilibrio estimado, previsto ou projetado - é o apresentado no orçamento e decorre da igualdade entre receita estimada e despesa fixada;

2. Equilibrio concomitante - é o observado durante a execução orçamentária e decorre de perfeito sincronismo entre a arrecadação das receitas e a efetivação das despesas;

3. Equilibrio efetivo ou realizado - é o que se verifica ao encerrar-se o exercício, em conseqüência do cômputo geral da gestão financeira; e

4. Equilibrio ciclico - é o que resulta da adaptação do orçamento aos ciclos econômicos, sendo o equilibrio verificado não durante um ano, mas durante largos períodos, em função das flutuações cíclicas da economia. 
O equilibrio cíclico será mais detalhadamente analisado quando fôr abordado o problema das crises cíclicas. Este tipo de equilibrio orçamentário, embora classificado pelo Prof. A. Barsante em razão das fases do processo orçamentário, foge um pouco dêste aspecto e se enquadra mais apropriadamente como medida de politica fiscal dentro de um esquema mais amplo de orientação governamental da economia, frente a situações conjunturais surgidas no evoluir histórico das economias desenvolvidas.

III - A POLÊMICA SÔBRE O PRINCÍPIO DO EQUILÍBRIO ORÇAMENTÁRIO

O princípio do equilibrio orçamentário não é um ponto inteiramente aceito pelos diversos autores e tratadistas sôbre orçamento público. Pelo contrário, êste princípio se tem prestado a intensas polêmicas, apresentando, tanto os seus condenadores como defensores, argumentos e razões sobejas para firmarem a posiçãc tomada.

Os chamados autores clássicos liberais defendem-no intransigentemente. Para êles o equilibrio constitui a essência do orçamento. É um verdadeiro dogma. Posteriormente, com as idéias lançadas por J. M. Keynes, na Inglaterra, formou-se uma respe:tável corrente defensora dos gastos públicos, não importando a ocorrência de «deficits», destinados a arrancar o sistema econômico da depressão conjuntural. Nas fases de prosperidade a ocorrência de «superavit» é medida grandemente defendida. Mais recentemente, com o surgimento do fenômeno do subdesenvolvimento, grande número de autores, preocupados com o enorme atraso que separa os países subdesenvolvidos dos que já atingiram alto grau de desenvolvimento, advogam o desenvolvimento econômico a qualquer preço, superpondo êste ao equilibrio das finanças governamentais e mesmo à estabilidade monetária .

Esta multiplicidade de idéias, ora defensoras, ora condenadoras do equilibrio orçamentário, talvez tenha deixado perplexo o leitor, sem the dar um ponto firme onde possa se orientar. Todavia, em uma análise mais detalhada e atenta das várias posições tomadas, chega-se à conclusão de que, em linhas gerais, todos os autores têm razão, desde que localizemos as suas idéias no tempo e nas condições em que se desenvolveram. A confusão havida é apenas de pressupostos, isto é, as condições econômico-socịais, que constituem a base sôbre a qual o orçamento desenvolve as suas funções, são bem diferentes em cada caso. Assim sendo, a existência do equilibrio orçamentário ou a ocorrência de «deficit» ou «superavit» são situações perfeitamente cabíveis desde que tais condições, determinadas pela evolução histórica dos fatos, assim o exijam. O grave êrro, que ocorre freqüentemente, é a tentativa 
de transpor idéias que se desenvolveram em épocas e condições determinadas para outra época e outras condições completamente diferentes.

Para se ter uma noção mais clara e consciente de como o principio do equilibrio orçamentário evoluiu de uma posição de aceitação indiscutivel e inatacável para transformar-se em instrumento subordinado à situação econômico-social de cada época, será feito um sucinto relato histórico das diversas fases da evolução econômica, correlacionando as com o equilíbrio orçamentário.

\section{IV - O EQUILÍBRIO ORÇAMENTÁRIO E AS TRANSFORMAÇÕES ECONÔMICAS}

Procura-se mostrar, neste estudo comparativo, como as grandes mutações das condições econômicas, verificadas no correr dos séculos, refletiram sôbre as idéias de equilibrio orçamentário. O ponto de partida será os albores do século XIX, época em que a «revolução industrial», iniciada na Inglaterra, já se estendera a quase tôda a Europa e transmitia-se fortemente à América. O liberalismo econômico era doutrina fundamental na época, formando-se, então, o que se costuma denominar de «teoria econômica
clássica».

\section{IV.1 - O equilibrio orçamentário e a «economia clássica»}

Caracterizava êste periodo inicial da revolução industrial a ênfase total que se dava à atividade privada para alcançar-se o ótimo da produção econômica. Cada pessoa trabalhando para si, em busca do máximo benefício individual, traria no final o benefício de todos. A «mão invisivel», referida por Adam Smith, guiava o sistema econômico, conduzindo-o ao melhor aproveitamento de seus recursos e à mais racional distribuição dos benefícios alcançados. A lei da oferta e da procura, determinando um sistema de preços espontâneo, mantinha o equilibrio da economia ao nivel de plena ocupação. Não se haviam formado ainda os sindicatos de trabalhadores ou patronais nem haviam aparecido os monopólios, já que as emprêsas funcionavam em pequenas unidades.

Neste quadro descrito, de pronto pode-se inferir que a intervenção governamental era extremamente combatida e tida como prejudicial ao equilibrio normal do sistema econômico. As funções do govêrno se restingiam ao mínimo indispensável, à manutenção da ordem interna e à defesa externa. É conhecidissima a frase clássica que bem reflete esta situação: «o melhor govêrno é aquêle que menos governa». As receitas necessárias ao financiamento dêstes gastos eram cobradas sôbre a forma de tributos gerais, sem 
a minima orientação econômica. $\mathrm{O}$ orçamento público, por conseguinte, não passava de um mero quadro contábil sem nenhum poder de ação econômica.

O princípio do equilibrio orçamentário, nestas condições, era norma essencial. Os governantes deveriam retirar da atividade privada apenas o estritamente correspondente aos gastos indispensáveis. Justificava-se assim a defesa intransigente feita pelos clássicos liberais ao princípio do equilibrio orçamentário. Tinham êles perfeita razão em agir desta maneira, já que as condições da época assim determinavam.

\section{IV.2 - O equilibrio orçamentátio e as flutuações ciclicas.}

O liberalismo que, como vimos, caracterizou esta primeira fase do processo de industrialização das nações capitalistas foi, todavia, perturbado por acontecimentos novos surgidos. Entre êstes se destacam as flutuações cíclicas da economia.

Observaram os economistas que as condições econômicas nunca são estáticas. O constante progresso das nações industrializadas tem-se processado não em uma linha reta e ascensional com as fôrças que atuam dentro do sistema perfeitamente em equilibrio. Pelo contrário, a prosperidade tem sido sempre seguida de um pânico ou colapso econômico. $\mathrm{Na}$ prosperidade, a renda nacional, o nivel de emprêgo, a produção, os preços, os lucros, a circulação monetária e, por via de conseqüência, a arrecadação sobem até ser atingido um «pico», constituindo, assim, a chamada fase de «expansão». Em seguida, desencadeia-se um processo inverso ou de "contração», onde a renda nacional, o nivel de emprêgo, a produção, os preços, os lucros, a arrecadação, enfim tôdas as macrovariáveis que antes haviam entrado em um processo de expansão iniciam uma marcha descensional até ser atingido um ponto de inflexão inferior chamado «cava» ou ponto de «recuperação», a partir do qual voltam a expandir, iniciando uma nova fase de prosperidade. Tais ciclos não são perfeitamente iguais nem ocorrem em espaços de tempo determinados, variando de 5 a 15 anos a sua duração. A famosa crise iniciada em 1929 nos Estados Unidos e estendida a quase todos os países indus trializados da época é um dos exemplos marcantes de depressão econômica. Entre as fases de prosperidade destacam-se as expansões ocorridas nos periodos que coincidiram com a deflagração das duas grandes guerras mundiais.

Estas novas condições surgidas no evoluir histórico das economias industrializadas fizeram com que se ampliassem grandemente as funções governamentais. As idéias lançadas na Inglaterra por Keynes, advogando a intervenção estatal através de grandes gastos públicos para reativar o sistema econômico, foram 
seguidas pelos economistas de Oxford e ràpidamente se transformaram em ação governamental.

O equilibrio orçamentário cíclico se verifica, então, quando os «deficits» da época de contração são compensados pelos «superavits» da época de expansão. Em época de contração deve o govêrno intensificar os gastos em grandes obras públicas e reduzir a tributação a fim de reativar a economia, provocando o crescimento da renda nacional, (1) o emprêgo da mão-de-obra, a utilização dos equipamentos paralisados, a movimentação da circulação monetária emperrada e a detenção da marcha descendente dos negócios.

Sabendo-se que as receitas governamentais tenderão forçosamente a cair em época de depressão, tal politica de aumento intensivo dos gastos públicos e ainda de diminuição dos encargos tributários só poderá gerar altos «deficits» orçamentários. Todavia, a época de expansão que se segue, com as receitas governamentais em ascensão e os encargos de investimentos e atendimento aos desempregados e famintos diminuidos sensivelmente, provocará as condições necessárias para que o govêrno busque, através do aumento da tributação e redução dos gastos, a formação de «superavits» orçamentários, compensando assim os «deficits» anteriores.

«A Dinamarca, a Finlândia e a Suécia criaram neste sentido os chamados fundos orçamentários ou de compensação, hauridos da prosperidade para a depressão e destinados a financiar grandes trabalhos» (Alberto Deodato, em Manual de Ciência das Finanças).

O leitor atento, a esta altura, já deve ter deduzido que a simples defesa do equilibrio orçamentário, na sua forma clássica,

(1) J. M. Keynes, para mostrar os efeitos de um incremento nos investimentos sôbre o total da renda nacional, quando a economia se acha com mão-de-obra desempregada e equipamentos não utilizados, desenvolveu o princípio do «multiplicador de investimento». Este principio mostra que um aumento de investimento autônomo fará com que a renda nacional aumente de uma quantidade maior que o aumento do investimento inicial.

Exemplo: o govêrno investe 10 bilhões de cruzeiros na construção de uma rodovia. Pelo principio do multiplicador de investimento a renda nacional será acrescida não apenas dos 10 bilhões, investidos pelo govêrno, mas de $10 \times 3$, logo, 30 bilhões, se o multiplicado: fôr 3 . O valor do multiplicador tagem de aumentonsão marginal a consumir da comunidade, isto é, da percenmo. Assim a renda renda que a comunidade destina para gastos em consuconsumo, novas rendas investimento inicial de 10 bilhões vai gerar, através do multiplicando o efeito que por sua vez geram outras rendas, indo assim métrica decrescente.

Todavia, se por qualquer motivo, tanto por ter a economia atingido o nivel de pleno emprêgo ou por estrangulamentos estruturais, não é possivel novos gastos em consumo, então o efeito multiplicador se propaga sôbre os preços. 
isto é, igualdade anual entre receita e despesa, foi superada pelos próprios fatos econômicos. Os governos, como foi visto, premidos por êstes fatos ocorridos no passar do tempo, foram obrigados a renunciar ao princípio do equilibrio orçamentário anual e admitir a presença de «defic ts» ou «superavits» que se compensariam em. cada ciclo, tendo em mira diminuir a ocorrência e os efeitos das perigosas flutuações econômicas.

Não se deseja aqui apenas criticar a posição dos clássicos liberais, que advogavam o principio do equilibrio orçamentário como a mais essencial característica do orçamento público, ou levar ao leitor a idéia apressada de que a procura de uma posição de equilibrio no orçamento deva ser simplesmente postergada. $\mathrm{O}$ que se deseja realmente mostrar, a fim de que se possa tomar uma posição consciente, frente à intensa polêmica que se desenvolve a respeito do princípio do equilibrio orçamentário, é que a igualdade entre receita e despesa se acha subordinada à situação mais ampla que é a da conjuntura econômico-social de cada país. Tal ocorrência só é possivel porque o orçamento deixou de ser um mero quadro contábil, para se tornar, modernamente, num poderoso instrumento de ação financeira, econômica e social.

IV.3 - O equilibrio otçamentátio e o pleno-emprêgo das economias desenvolvidas.

A busca do pleno-emprêgo pelas nações de economias desenvolvidas surgiu como reação à ocorrência das flutuações cíclicas. Através de uma ativa política fiscal, juntamente com amplas medidas de política monetária e cambial, têm os governantes dêstes países procurado não mais apenas minorar os efeitos das flutuações cíclicas, mas manter o pleno-emprêgo dos recursos produtivos, o que tem permitido que o crescimento econômico se tenha, então, tornado um processo contínuo e equilibrado. Tal corpo de idéias forma o que se conhece por «política do pleno-emprêgo», que se constitui atualmente na meta principal dos governos dêstes países.

Dentro desta política, o problema da igualdade entre receita e despesa orçamentárias desaparece para dar lugar à formação de «superavits», através da redução dos gastos e ampliação da tributação, quando a economia ultrapassa o nivel do pleno-emprêgo e entra na fase das pressões inflacionárias.

\section{IV.3 - O equilibrio orçamentátio e as economias subdesenvol vidas.}

Outro ponto importantíssimo a ser levado em consideração ao se estudar as repercussões de uma situação de equilibrio orçamentário é o surgimento das economias chamadas subdesenvolvidas, mormente porque entre elas se acha classificado o Brasil. 
O subdesenvolvimento é definido como uma situação de atraso de um grande número de nações com relação àquelas que conseguiram alcançar alto grau de desenvolvimento. Esta situação de subdesenvolvimento se reflete, principalmente, num baixo nivel de renda «per capita», carência de capitais, concentração de renda, falta de integração, alta taxa de crescimento demográfico, maior número da população ativa ocupada em atividades primárias, alta taxa de analfabetos, desemprêgo disfarçado, carência de mão-de-obra especializada e a presença de um processo inflacionário persistente.

Estas condições descritas, que caracterizam os paises subdesenvolvidos, são bem diferentes daquelas que existiram no liberalismo do início do século XIX, no decorrer das flutuações cíclicas e no atual estágio das economias desenvolvidas. Em consequiência desta disparidade de condições, a politica fiscal dos paises subdesenvolvidos não pode ser extraída de modelos que são próprios para outras situações. Pelo contrário, êsses paises têm que levar em conta, ao encetarem sua política fiscal, aquelas condições peculiares ao subdesenvolvimento que foram descritas, tendo como principal meta a eliminação do atraso econômico e social em que se encontram.

O Brasil, classificado no rol dos subdesenvolvidos, tem que orientar sua política fiscal nesse sentido.

O principio do equilibrio orçamentário, então, deve ser colocado em função dessa meta mais ampla. Neste caso, para que se possa penetrar no verdadeiro sentido que representa o equilibrio orçamentário na atual situação brasileira, deve-se antes entender como atua o orçamento público, modernamente, sendo capaz de apresentar-se como «instrumento de programação da atividade governamental e de orientação e contrôle da economia nacional». Isto será feito através de um sucinto estudo das funções financeiras, econômicas e sociais da tributação e dos gastos públicos.

V - FUNÇÕES FINANCEIRAS, ECONÔMICAS E SOCIAIS DA TRIBUTAÇÃo E DOS GASTOS PÚBLICOS NO ESTÁGIO ATUAL.

V.1 - Funções da tributação:

V.1.1 - função financeira - arrecadação de recursos monetários para financiar a atividade governamental;

V.1.2 - função social - redistribuição de renda, reduzindo as desigualdades individuais e regionais; e

V.1.3 - funções econômicas:

a) sôbre o sistema produtivo - estimular a produção de bens e serviços. Neste sentido, o Impôsto de Importação é arma va- 
liosíssima, pois que, quando bem orientado, pode proteger adequadamente a indústria nascente contra a poderosa concorrência estrangeira. Vale aqui ressaltar que a industrialização brasileira se vem verificando como um constante processo de substituição de importações e para tanto o Impôsto de Importação, protecionista, tem sido fator decisivo. No setor primário da economia, a tribu tação sôbre a propriedade rural, penalizando as áreas improdutivas e oferecendo isenções às que se mostrarem produtivas, é instrumento eficaz no estímulo à produção de alimentos. Deve-se advertir que a tributação também se mostra como desestimulante da produção desde que se verifique má orientação na política fiscal que procure arrecadar cada vez mais sem se preocupar com os efeitos negativos da carga excessiva ou quando busca deliberadamente o govêrno diminuir a produção de certos bens e serviços como medida de ordem econômica e social;

b) sôbre o nivel de consumo - permitir maior consumo de gêneros de primeira necessidade em virtude de redução ou isenção total do Impôsto de Consumo sôbre êstes bens. No Brasil, a própria Constituição Federal resguarda da cobrança do Impôsto de Consumo os artigos que a lei classificar como o mínimo indispensável à habitação, vestuário, alimentação e tratamento médico das pessoas de restrita capacidade econômica. O Impôsto de Consumo também é instrumento auxiliar no combate à inflação através do aumento das aliquotas sôbre bens supérfluos ou ostentatórios, procurando, por esta via, comprimir a demanda;

c) sôbre o nível de poupança - incentivar a poupança privada através do Impôsto de Consumo seletivo que taxe mais pesadamente o consumo supérfluo, forçando a poupança de parte dos rendimentos. A tributação pode resultar em formação de poupança por parte do govêrno através de «superavit» do orçamento corrente;

d) sôbre o nivel de investimento - estimular a reinversão de lucros das emprêsas através da redução ou isenção do Impôsto de Renda sôbre lucros reinvestidos. Reduzir a remessa de lucros para o exterior, procurando que êles permaneçam no país e sejam reinvestidos, isentando os que assim agirem.

\section{V.2 - Funções dos gastos públicos.}

V.2.1 - função financeira - desembôlso de recursos monetários para pagamento de despesas realizadas na satisfação das necessidades públicas;

V.2.2 - função social - promoção do bem-estar social; e V.2.3 - funções econômicas:

a) mobilização de recursos produtivos - verifica-se que por trás dos gastos monetários efetuados pelo govêrno o que ocorre é 
uma transferência de fatôres produtivos (homens, máquinas e terras) que antes se achavam empregados na atividade privada para o setor público bem como a utilização de recursos antes paralisados;

b) aumento da produção nacional - o crescimento do produto nacional resultante dos gastos públicos é possivel quando a aplicação dos recursos se verifica em empreendimentos produtivos, substituindo a aplicação não produtiva ou menos eficiente do setor privado, ou pela utilização de recursos que se encontram parados;

c) incremento da taxa de investimento - a taxa de investimento da economia pode ser acrescida através do incremento nos gastos em investimento do setor público, principalmente quando os recursos liberados para êste fim não resultam da compressão dos investimentos privados, mas sim de recursos subtraidos ao consumo excedente ou à poupança voluntária;

d) aumento do nivel de emprêgo - os gastos governamentais podem provocar a absorção por parte do setor público da mão-de-obra desempregada;

e) formação da infra-estrutura básica - ao govêrno tem cabido quase que total responsabilidade, principalmente nos paises subdesenvolvidos, na formação básica da infra-estrutura econômica. Tal ocorrência deve-se ao pouco interêsse que, tais empreendimentos (sistema de comunicações, vias de transportes, energia elétrica) despertam na atividade privada, já que são de longa maturação, como é o caso de construção de estradas, portos, hidrelétricas, reprêsas etc. ou porque constituem atividades consideradas estratégicas para a segurança nacional, como o telégrafo, telefone, extração de petróleo e outras.

\section{VI - A META DO EQUILÍBRIO ORÇAMENTÁRIO NO PLANO DE AÇÃO ECONÔMICA DO GOVÊRNO (PAEG)}

A politica fiscal brasileira, um dos principais instrumentos do Plano de Ação Econômica do Govêrno, orienta-se para dois pontos básicos, a saber: desenvolvimento econômico e redução do processo inflacionário. Êstes dois objetivos se traduzem no aumento da taxa do produto real «per capita» e na eliminação da participação do «deficit» orçamentário no Produto Interno Bruto (PIB).

A necessidade de reduzir o processo inflacionário é indiscutível. Ao ter atingido indices altíssimos, a inflação brasileira transformara-se em fator negativo ao desenvolvimento econômico. Assim é que, a partir de 1962, o Produto Interno Bruto começou a cair até atingir indices negativos enquanto a taxa de inflação aumentava aceleradamente. Os efeitos benéficos ao desenvolvimento econômico que uma inflação moderada pode trazer e já admitidos pelos economistas, tais como: formadora de «poupan- 
ças forçadas» e criadora de um ambiente animador ao ritmo dos negócios, deixaram de existir.

A pressão que vem causando, nos últimos anos, os «deficits» orçamentários sôbre a economia brasileira, tem-se transformado num dos principais aceleradores do processo inflacionário. Em tabela constante da página final, sob o título: «Deficit» de Caixa da União em Percentagem sôbre o PIB, o leitor poderá acompanhar o crescimento desta participação, bem como a sua redução e estimativa de completa extinção em 1967.

O equilíbrio orçamentário, então, passa a ser desejado tendo em vista a atual conjuntura econômica brasileira. Todavia, a efetivação do equilibrio orçamentário não pode entrar em choque com a outra meta básica - o desenvolvimento econômico. Nestas condições, a política fiscal tem que ser orientada numa cuidadosa coerência: aumentar a receita sem, todavia, desestimular os investimentos privados; por outro lado, reduzir as despesas sem comprimir os gastos em investimento, pois que a meta do desenvolvimento econômico se consubstancia num elevado esfôrço de capitalização, o que deve ser ação conjugada do setor privado e do setor público. (1)

Para obtenção do equilibrio orçamentário e, ao mesmo tempo, elevação da taxa de investimento, a política fiscal, dentro do Plano de Ação Econômica do Govêrno, se orienta no seguinte sentido:

a) refôrço da receita tributária da União e compressão da percentagem das suas despesas de custeio e transferência no PIB;

b) compressão do "deficit» de custeio de autarquias e sociedades de economia mista, através de uma política de realismo de tarifas e custos e da racionalização dos seus serviços;

(1) Para obter-se um crescimento do PIB de 6\%, que é meta do PAEG para 1966 e 1967, será necessário um investimento bruto (público e privado) da ordem de $17 \%$ do PIB. Em 1965, o Balanço dos Investimentos Públicos mostrou uma participação de $10 \%$ do PIB por parte do govêrno no esfôrço de capitalização. Esta participação não deve decrescer em 1966 e 1967 para que seja obtido o crescimento de $6 \%$ desejado.

O cálculo do montante de investimento necessário para obtenção de um crescimento desejado do Produto Interno Bruto é feito através da seguinte fórmula:

$$
\triangle P I B=\frac{S-d}{\rho}
$$

$\mathrm{S}$ - taxa bruta de investimento (17\%)

d - proporção da depreciação no PIB $(5 \%)$

v - relação incremental capital/produto (2)

$$
\triangle P I B=\frac{17 \%-5 \%}{2}=6 \%
$$


c) concessão de estímulos tributários à reinversão dos lucros das emprêsas e à formação de economias pessoais, e forte tributação do consumo supérfluo; e

d) restauração do prestígio dos títulos públicos, usando-os como adequada fonte de recursos para investimentos.

Estas medidas se completam com a introdução do OrçamentoPrograma, sendo colocados na lei orçamentária, além da classificação das despesas em programas, os diversos projetos e atividades dos órgãos executores.

Em linhas gerais, estas diretrizes se acham contidas na Proposta Orçamentária da União para o Exercício de 1967, onde a meta do equilibrio orçamentário se acha pràticamente assegurada. Quanto à meta do desenvolvimento econômico, traduzido êste na visão parcial do crescimento do produto real «per capita», as estatísticas são ainda precárias. Todavia, alguns dados provisórios já publicados indicam uma recuperação muito lenta. Tal situação deve-se, provàvelmente, ao processo de reajuste e adaptações por que vem passando o sistema econômico brasileiro, onde as distorções trazidas pela inflação foram grandes, e também ao retardamento de medidas mais profundas que visem às inadaptações estruturais, completando assim as vigorosas medidas tomadas no campo monetário.

\section{BIBLIOGRAFIA:}

SAMuELSON, P. A. - Introdução à Análise Econômica - $5^{a}$ edição -
umes I e II. Volumes I e II.
Deodato, Alberto - Manual de Ciência das Finanças - $8^{a}$ edição. BALEEIRo, Aliomar - Uma Introdução à Ciência das Finanças $-2^{3}$ edi-
ção - Vols. 1 e 2 . Barsante, Antônio - Curso de Administração Financeira - Departamen-
to Administrativo do Serviço Público.

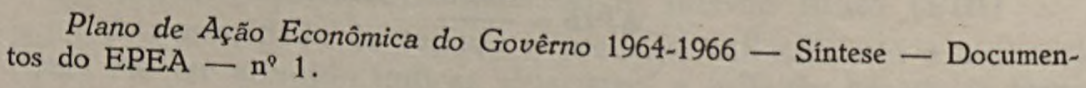
Mensagem do Presidente da República ao Congresso Nacional apresentan-
do a Proposta Orçamentária para o Exercício de 1967. Balanço dos Investimentos Püblicos - 1965 - Ministério do Planejamento
e Coordenação Econômica, Setor de Orçamento e Finanças - Grupo de Acom-
panhamento do Programa de Investimentos. 
«DEFICIT» DE CAIXA DA UNIAO EM PERCENTAGEM SOBRE O PIB

ANO
1954
1955
1956
1957
1958
1959
1960
1961
1962
1963
1964
1965
1966 (1)
1967 (2)

(em bilhões de $\mathrm{Cr} \$$ ) «Deficit» a preços correntes «Deficit»/PIB

\begin{tabular}{rr}
4,0 & 0,7 \\
5,7 & 0,8 \\
19,3 & 2,2 \\
40,9 & 3,9 \\
28,4 & 2,2 \\
53,7 & 3,0 \\
77,7 & 3,3 \\
130,4 & 3,7 \\
280,9 & 5,0 \\
504,2 & 5,1 \\
700,0 & 3,6 \\
587,0 & 1,8 \\
420,0 & 0,9 \\
\hline
\end{tabular}

\section{DISTRIBUIÇÃO PERCENTUAL DOS GASTOS DO ORÇAMENTO} FEDERAL ENTRE CUSTEIO E INVESTIMENTO

\begin{tabular}{|c|c|c|}
\hline ANO & $\begin{array}{c}\text { Custeio } \\
\%\end{array}$ & Investimento \\
\hline 1956 & 82 & 18 \\
\hline $\begin{array}{l}1957 \\
1958\end{array}$ & $\begin{array}{l}73 \\
73\end{array}$ & $\begin{array}{l}27 \\
27\end{array}$ \\
\hline 1959 & 65 & 35 \\
\hline 1960 & 62 & 38 \\
\hline 1961 & 82 & 18 \\
\hline 1962 & 82 & 18 \\
\hline 1963 & 82 & 18 \\
\hline $\begin{array}{l}1964 \\
1965\end{array}$ & $\begin{array}{l}79 \\
69\end{array}$ & $\begin{array}{l}21 \\
31\end{array}$ \\
\hline 1966 (1) & 69 & 31 \\
\hline 1967 (2) & 67 & 33 \\
\hline
\end{tabular}

(1) Execuçăo provável.

(2) Proposta Orçamentária.

FONTE: Mensagem do Presidente da República ao Congresso Nacional encaminhando a Proposta Orçamentária para o Exercicio de 1967. 